\title{
Cognitive Skills Matter: The Employment Disadvantage of Low-Educated Workers in Comparative Perspective
}

\author{
Aurélien Abrassart
}

Abstract: It is now a widely acknowledged fact that the low-educated workers are facing important risks of labour market exclusion in modern economies. However, possessing low levels of educational qualifications leads to very different situations from one country to another, as the cross-national variation in the unemployment rates of these workers attest. While conventional wisdom usually blames welfare states and the resulting rigidity of labour markets for the low employment opportunities of low-educated workers, empirical evidence tends to contradict this predominant view. Using microdata from the International Adult Literacy Survey that was conducted between 1994 and 1998, we examine the sources of the cross-national variation in the employment disadvantage of low-educated workers in 14 industrialized nations. In particular, we test the validity of the conventional theories concerning the supposedly harmful effect of labour market regulation against a new and promising hypothesis on the importance of cognitive skills for the employment opportunities of the low-educated workers. Our findings support the latter and suggest that the greater the cognitive gap between the low-educated workers and those with intermediate education, the lower the chances of being employed for the former relatively to their higher educated counterparts.

\section{Introduction}

Since the end of the Golden Age of Capitalism, loweducated workers seem to be increasingly disadvantaged in the labour market in industrialized countries. While this disadvantage was always present, its growth over the past decades has caused rising concern among scholars over the labour market situation of this group of workers and its consequences in terms of the new social risks it brings upon them (e.g. Huber and Stephens, 2006; Bonoli, 2007).

When one wishes to understand the detrimental economic and social outcomes of being low educated in modern nations, examining workers' employment status is probably the best way to start. Since important spells of unemployment can harm earnings, both in a short- and long-term perspective, and can also negatively affect the psychological well-being of workers (Machin and Manning, 1998), this labour market outcome is key in the constitution of the disadvantage that plagues the low-educated workers in industrialized countries.

However, as several Organisation for Economic Co-operation and Development (OECD) reports show (e.g. OECD, 2011), the employment rates of this particular group of workers, whether in absolute or relative terms, vary importantly across labour markets. Conventional wisdom has it, to over-simplify, that it is the rigidity of labour markets resulting from its regulation that is essentially responsible for the lower employment opportunities of the low-educated workers in some industrialized countries (e.g. OECD, 1994; Siebert, 1997). More particularly, wage regulation, the strictness of employment protection legislation, and the generosity of social benefits are believed to be at the root of this disadvantage. Yet, increasing empirical evidence (EspingAndersen, 2000; Howell, 2003; DiPrete, 2005; Bradley and Stephens, 2007) is adding controversy to the relevance of the previous theoretical arguments as

IDHEAP, Swiss Graduate School of Public Administration, Quartier UNIL Mouline, CH-1015 Lausanne, Switzerland. Email: aurelien.abrassart@idheap.unil.ch 
many European countries characterized by rigid labour markets fare actually better than traditionally flexible labour markets such as the United States in terms of employment, especially when focusing on the low-educated workers (Howell, 2003; DiPrete, 2005).

While scholars, think tanks, and policymakers, following conventional wisdom, have been essentially focusing on the role of labour market regulation in this issue, promising hypotheses also point at the potential importance of human capital formation policies and more particularly the development of cognitive skills in this issue. Because individuals with low cognitive abilities are less likely to attend high levels of education and since education certainly contributes to the development of those skills (Heckman, 2000), educational attainment is generally considered as a good measure of the level of cognitive skills workers possess. Yet, recent evidence has shown that cognitive gaps by educational attainment vary importantly across countries, especially when focusing on the low-educated workers (Park and Kiey, 2011).

While educational attainment constitutes in itself a strong signal for employers regarding workers' potential productivity, the fact that the low-educated workers and their better educated counterparts possess relatively close levels of cognitive skills may well mean better employment opportunities for the former as these skills have been shown to matter a great deal at the individual level, independently of formal educational qualifications (e.g. Pryor and Schaffer, 1999; McIntosh and Vignoles, 2000; Heckman, Stixrud and Urzua, 2006), while the average level of competence of the low-educated group is likely to affect employers' hiring decision through the strong signal it sends regarding their trainability potential (Solga, 2002; Gesthuizen, Solga and Künster, 2011).

Accordingly, determining whether it is rather this new perspective than the more traditional labour market regulation hypothesis that plays a significant role in the relative employment opportunities of the low-educated workers will be our main interest in this article.

\section{Theoretical Background}

\section{Labour Market Regulation and the Employment Opportunities of the Low-Educated}

Several elements of labour market regulation are generally believed to affect the employment opportunities of workers with low educational qualifications. First, permanent employment protection legislation may accentuate the risks of long-term unemployment for the low-educated workers as it reduces their mobility-less hiring during upswings and less firing during downturns-and therefore the outflows of unemployment, essentially affecting the weakest groups of workers, among which are the low-educated (Esping-Andersen, 2000; Oesch, 2010). That is, unless countries characterized by more rigid labour markets decide to introduce flexibilization at the margin, through a deregulation in the use of fixed-term contracts, as several European countries have already done (e.g. DiPrete, 2005). However, these precarious contracts, essentially pertaining to the youth and the low-educated workers (OECD, 2002), because they are also less secure, may in the end not necessarily improve the employment opportunities of the latter.

Second, social benefits generosity may further move the low-educated workers away from the labour market as this generosity, whether in terms of amount, entitlement, or duration, will increase the reservation wages of this category of workers. However, while these passive labour market policies are believed to negatively affect the employment opportunities of the low-educated workers, active labour market policies (ALMPs) such as public employment services or training measures, on the other hand, may counterbalance the negative effect of the former and help the low-educated workers integrate or re-integrate the labour market (Esping-Andersen, 2000; Oesch, 2010). According to Oesch (2010) and Nordlund (2011), ALMPs will help the unemployed find a job in two main ways: first, through training measures, they will improve the human capital of unemployed workers; second, through employment services and individual case management, they will enhance social networks and keep the beneficiaries of these measures motivated to find a job.

\section{The Cognitive Gap and the Employability of the Low-Educated}

As a growing literature suggests, cognitive skills are becoming crucial to deal with the rising complexity of jobs in modern economies (e.g. Murnane, Willett and Levy, 1995; Carbonaro, 2007). In the last decades, skill-biased technological change (SBTC), through computerization, has indeed importantly contributed to the reduction of labour associated to routine manual and cognitive tasks while causing the development of non-routine cognitive tasks demanding more 'flexibility, creativity, generalized problem-solving capabilities, and complex communications' (Autor, Levy and Murnane, 2003).

Since cognitive skills are predictive of job performance (Farkas et al., 1997), it is thus perfectly normal that employers care about their employees possessing the 
right skills to be successful in modern economies and reward them accordingly. And since the allocation of human capital in the labour market depends on two processes, hiring and firing, for employees, this is thus not only a matter of retaining a job but also of getting a job. For employers, the difficulty then lies in a way to assess workers' skills before hiring them. Whether it is through the use of written tests, or during interviews, where 'cues such as grammar, vocabulary, comprehension of questions, and logical relevance of answers' give hints about the level of skills of applicants, or through networks, school reputation, grades, and educational attainment, employers have many ways to screen future employees according to their skills (Farkas et al., 1997). As these authors nicely summarize,

At one extreme, skills may be so difficult to measure, and particularistic social connections so compelling, that good jobs and high earnings are virtually uncorrelated with real skill levels. At the other extreme, employers may be so focused on skills and so enterprising in their pursuit of indicators highly correlated with such skills that they typically succeed in solving their information problems. In this event, returns to skill may be quite high.

Accordingly, the cognitive gap, that is the difference in the average level of cognitive skills between the low-educated and those with intermediate education, is likely to play an important role in the explanation of the extent of the employment disadvantage of the former, and this for two reasons. First, because the greater the cognitive gap, the higher the risk that the low-educated workers will not be able to compete with higher educated workers during interviews, and on the job as they will likely lag behind in terms of job performance due to the increasing complexity of tasks at work. Second, as a recent stream of literature suggests (e.g. Solga, 2002; Gesthuizen, Solga and Künster, 2011), the average level of competences of the low-educated group may also be an important determinant of the employability of these workers because of the signal it sends to employers regarding applicants' basic skills and therefore their trainability potential. In other words, the lower the average level of cognitive skills of the low-educated workers, the greater the stigmatizing effect of being low-educated and therefore the greater the probability that these workers will be statistically discriminated by employers who trust the sorting function of educational systems. Accordingly, the larger the cognitive gap, the greater the chances that possessing only low formal educational qualifications will be seen by employers as a sign of a lack of cognitive skills.
Against this background, in countries where the low-educated workers are more likely to be laggards in terms of cognitive skills relatively to their more educated counterparts, the former should also be more likely to be disadvantaged in terms of employment, still relatively to the latter.

\section{Polarization of the Labour Market and Job Displacement Patterns}

However, since it seems that some modern labour markets are, in fact, witnessing a polarization of occupations rather than only an occupational upgrading (Autor and Dorn, 2009; Oesch and Menés, 2010), it is legitimate to doubt about the role cognitive skills may play in the employment disadvantage of the low-educated workers. Indeed, while these skills may be crucial to perform highly complex tasks, they are less likely to matter for job performance-and therefore employers-in jobs with basic repetitive tasks. And since this polarization of labour markets is partly due to the development of low-end service jobs that are less affected by SBTC (Oesch and Menés, 2010) and therefore are characterized by low skill requirements, an important cognitive gap may not necessarily result in a higher employment disadvantage for the low-educated workers. In other words, the cognitive disadvantage of the low-educated workers may not necessarily further keep off the former out of the labour market if there is a sufficient supply of jobs with low skill requirements, such as in low-end services.

Yet, since this polarization is likely to reflect the fact that 'middling' jobs are disappearing while high- and low-end service jobs are created (de Grip and Zwick, 2004), then those who were occupying these mid-level jobs and who probably have intermediate education will be more likely to go down the occupational ladder and to compete with the low-educated for low-end jobs, eventually resulting in the former displacing the latter from their traditional occupations. This would induce a greater effect of the cognitive gap on inequality of employment opportunities between low-educated workers and those with intermediate education as employers would be more likely to favour those with higher levels of cognitive skills if both categories of workers are found to compete for the same jobs.

\section{Data and Methods}

\section{Data Description}

The data we have used for our empirical analysis come from the International Adult Literacy Survey (IALS) that 
was conducted in a total of 20 countries between 1994 and 1998. This survey was administered in order to assess the literacy skills of the adult population in an international perspective. The following countries were included in our analysis: Canada, Switzerland, Germany, the United States, Ireland, the Netherlands, Sweden, New Zealand, the United Kingdom, Belgium, Italy, Norway, Denmark, and finally Finland.

\section{Methodology}

The methodological technique that we use here is the estimated dependent variable model (Lewis and Linzer, 2005), also referred to as a two-step or two-stage multilevel model, consisting in estimating the same equation in several groups and using the coefficients of one or several independent variables of interest from this equation in order to try to explain the cross-group variation in these coefficients. In our case, in the first stage of our analysis, this will consist in estimating the effect of being low-educated on the employment status at the individual level in each country, while the second step of the model will be dedicated to the explanation of the cross-national variation in this effect through the introduction of country-level variables.

Compared with the more traditional multilevel model, the two-step approach presents several advantages, among which the more flexible specification of individual-level effects that 'are allowed to vary across countries [...] without imposing any further distributional assumptions' (Leoni, 2009; Gebel and Giesecke, 2011). Another advantage lies in the number of observations required at the second level to obtain robust findings. Since we only include 14 countries in our sample, it is more reliable to use this technique as it allows an easier correction of heteroskedasticity at the second level than when using maximum likelihood estimation (Maas and Hox, 2004; Nelson, 2009).

\section{First Stage of Analysis}

\section{Dependent variable}

Throughout this article, our dependent variable is measured through the working/not working distinction, rather than the employed/unemployed dichotomy, in order to include all individuals out of the labour market and not only those who are actively looking for work. Indeed, unemployment rates, because they only account for workers looking for a job actively, miss an important part of the non-working population, especially in the case of low-educated workers who are more likely to experience long-term unemployment and may therefore be more likely to become discouraged workers. To avoid the danger of including workers who have retired at the legal age and students who have not completed their education yet, we decided to only keep the prime working age respondents, namely those whose age is between 26 and 55 years.

The main issue related to using the working/not working distinction pertains to the inclusion of voluntary unemployed workers who are found out of the labour market because of care duties or other reasons that may appear at first exogenously determined. And this problem may be particularly acute in the case of married women who, we can reasonably assume, are more likely to become home makers as a result of the national cultural and political factors (Daly, 2000; Oesch, 2010).

However, it can be extremely difficult to find out with certitude if people are voluntarily choosing to get into or stay out of the labour market as this apparently deliberate choice may be the result of a lack of opportunities in the labour market. Yet, to make sure that our findings are robust and therefore reliable, we conducted sensitivity analysis by estimating our models separately for men and women. Despite a slight fall of significativity at both levels, our results and conclusions remain virtually the same. Mainly for reasons of significativity, we therefore proceeded with our analysis without separating the male and female respondents in our sample but anyway controlled for gender at the individual level to account for gender differences in the likelihood of employment and to obtain unbiased measures of the effect of education on employment status.

\section{Independent variable}

Our main independent variable in the first stage of our analysis was measured through the educational attainment of respondents, coded in three categories: below upper secondary education [International Standard Classification of Education (ISCED) 0-2], intermediate education (ISCED 3) and tertiary education (ISCED 5-7). ${ }^{1}$ The reference category of this variable will be below upper secondary education so that the coefficient of the intermediate education category can reflect the employment advantage the medium-educated experience relatively to the former.

However, two of these countries, namely the United Kingdom and Germany presented severe issues concerning the variable indicating educational attainment. Indeed, as Gesthuizen, Solga and Künster (2011) have observed, the proportion of low-educated workers in these countries was clearly higher in the IALS sample than in OECD reports. Basing ourselves on the number of years of schooling that was reported by respondents 
and depending on the length of compulsory schooling, we recoded the variable of educational attainment following almost the same procedure as the one of Gesthuizen, Solga and Künster (2011). ${ }^{2}$ Accordingly, depending on cohorts, workers with lower secondary education (ISCED 2) who declared that they had more years of schooling than the nationally possible years of compulsory schooling were thus 'upgraded' in the ISCED 3 category. ${ }^{3}$ First-generation immigrants were excluded from this recoding because they are more likely to have already completed their education in their home country.

\section{Control variables}

To obtain unbiased coefficient for the influence of education on the probability to be in or out of the labour market and to account for compositional effects, we had to control for other important determining factors for this labour market outcome. These encompass age (which is mainly a proxy for labour market experience), immigrant status (only the first generation, i.e. those workers who were born outside the country of interview), gender, parental background, which was measured through mothers' education coded in three categories, ISCED 0-2, ISCED 3, and ISCED 5-7, and finally a variable indicating the size of the community that was defined as either urban or rural. ${ }^{4}$

The model at the first stage

The model at the first stage can be written as follows:

$$
\begin{aligned}
\mathrm{W}_{\mathrm{ij}}= & \alpha_{\mathrm{ij}}+\mathrm{E}_{1 \mathrm{ij}} \beta_{1 \mathrm{ij}}+\mathrm{E}_{2 \mathrm{ij}} \beta_{2 \mathrm{ij}}+\mathrm{F}_{\mathrm{ij}} \beta_{3 \mathrm{ij}}+\mathrm{A}_{1 \mathrm{ij}} \beta_{4 \mathrm{ij}}+\mathrm{A}_{2 \mathrm{ij}} \beta_{5 \mathrm{ij}} \\
& +\mathrm{I}_{\mathrm{ij}} \beta_{6 \mathrm{ij}}+\mathrm{M}_{1 \mathrm{ij}} \beta_{7 \mathrm{ij}}+\mathrm{M}_{2 \mathrm{ij}} \beta_{8 \mathrm{ij}}+\mathrm{U}_{\mathrm{ij}} \beta_{9 \mathrm{ij}}+\varepsilon_{\mathrm{ij}}
\end{aligned}
$$

where $\mathrm{i}$ stands for individuals and $\mathrm{j}$ for country. $\mathrm{W}$ is our binary dependent variable (working/not working), $\mathrm{E}_{1}$ and $E_{2}$ stands for, respectively, intermediate education (ISCED 3) and high education (ISCED 5-7), $\mathrm{F}$ for female, $A_{1}$ and $A_{2}$ for the age in categories (respectively 36-45 and 46-55 years with the reference category being 26-35 years), $I$ for immigrant status, $M_{1}$ and $M_{2}$ for mothers' education in categories, and finally $\mathrm{U}$ for urban community.

Accordingly, we first estimated, in each country included in our analysis, the effect of education on employment status (working/not working), while controlling for the other covariates described earlier. Average marginal effects (AMEs) were used to estimate the effect of our independent variables on the employment status since the comparison of coefficients across groups can easily be biased when using logit regressions (Mood, 2010). By using AMEs, our coefficients will reflect the effect of our independent variables on the dependent variable in terms of the change on the probability of being employed at the time of survey. Robust standard errors were obtained using the sandwich estimator (also known as the Hubert/White estimator).

\section{Second Stage of Analysis}

\section{Dependent variable}

At the second stage of our analysis, the coefficients of our main independent variable at the individual level estimated in each country, namely the AMEs of an intermediate level of education relatively to a low level of education on the employment probability, now becomes our dependent variable.

\section{Independent variables}

The country-level variables ${ }^{5}$ that were then included in our model to explain the cross-national variation in this disadvantage encompass:

- employment protection, measured through the index of permanent employment protection legislation and averaged over a 3 -year period $(\mathrm{t}-2, \mathrm{t}-1, \mathrm{t})$;

- social benefits generosity, measured through the index of decommodification built by Scruggs and Allan (2006);

- spending on two particular categories of ALMPs, ${ }^{6}$ public employment service and administration, and training, expressed in per cent of gross domestic product (GDP), divided by unemployment rates and averaged over a 3-year period;

- the ratio of the adjusted mean ${ }^{7}$ of the literacy scores of those with intermediate education to the adjusted mean of the literacy scores of the low-educated workers, calculated in each country, and measuring the national cognitive gap between these two groups. Functional literacy, which regroups prose, document and quantitative literacy, ${ }^{8}$ is used here as a proxy for the cognitive skills that are expected to matter for the employment status of workers. This measure is particularly adequate in our case as it assesses the reading, writing, and arithmetic knowledge and skills required in real life and especially work situations (Pryor and Schaffer, 1999). These consist, for instance, in understanding and using information from editorials, stories, job applications, tables, and graphics, as well as applying arithmetic operations such as balancing a chequebook or determining the amount of interest on a loan from an advertisement (IALS microdata user's guide); and 
- finally two variables measuring the skill demand of jobs ${ }^{9}$ held respectively by medium-educated and low-educated workers to account for the extent of job displacement that the former impose to the latter. More precisely, we believe that the effect of the skill demand of jobs of medium-educated workers while controlling for the skill demand of jobs held by the low-educated workers should constitute a good measure of job displacement as it determines the relative difference in the skill demand in the labour market between these two groups of workers. The closer both skill demands are, the greater the chances that medium-educated are, crowding out the low-educated workers from their traditional occupations.

\section{The models at the second stage}

The models at the second stage can be written as follows:

$$
\begin{gathered}
\beta_{1 j}=\Phi_{0 j}+\Phi_{k j} V_{k j}+\varepsilon_{j} \\
\beta_{1 j}=\Phi_{0 j}+\Phi_{1 j} V_{1 j}+\ldots+\Phi_{k j} V_{k j}+\varepsilon_{j},
\end{gathered}
$$

where (2) is the equation for the bivariate models (one variable at a time) and (3) is the equation for the multivariate models. As already explained before, the coefficient $\beta_{1 j}$ measuring the estimated effect of intermediate education relatively to low education on employment chances at the individual level in each country now becomes our new dependent variable. Again, $j$ stands for the 14 countries included in the analysis, and finally $\mathrm{V}_{\mathrm{k}}$ for the aforementioned countrylevel independent variables.

Feasible generalized least squares were used here with the edvreg command on Stata (Lewis and Linzer, 2005). Since our dependent variable at the second level is a coefficient and is therefore estimated with error, this procedure allows us to account for the variation across countries in the degree of imprecision with which our dependent variable is estimated. Finally, robust standard errors were obtained with the Efron estimator that has been shown to give better results with small sample sizes (Long and Ervin, 2000).

\section{Endogeneity Issues}

Since literacy skills were measured at the same time of the interview, people out of the labour market for already a long period could have lost part of these skills, while those working are more likely to enhance these skills. This thus makes the causal relationship between skills and employment status less straightforward and therefore could cause problems of endogeneity as a result of this reverse causality, especially knowing that some respondents declared having been unemployed or looking for work for more than 40 years. But the strength of the effect of the length of unemployment on cognitive skills is probably limited as Pryor and Schaffer (1999) argue, as is the strength of the effect of age ${ }^{10}$ and experience on the same skills (Gesthuizen, Solga and Künster., 2011).

Moreover, when observing the mean literacy scores of those out of the labour market in each country (Figure 1), it doesn't seem at all that respondents who have declared not having worked for 10 or more years possess less skills than other more 'recent' unemployed. Therefore, the risk that the length of the spells of unemployment may negatively affect functional literacy is very low.

\section{Findings}

As we have previously explained, the first step of our model consists in estimating the relative employment disadvantage of the low-educated workers in each country while controlling for other important factors of labour market participation. As we can observe in Table 1, even after controlling for all these determinants, the relative disadvantage of the low-educated workers in terms of employment varies importantly across countries. More interestingly, the ranking of countries in terms of the employment disadvantage of the loweducated workers does not seem to follow any known welfare or labour market regime classification. In particular, while we could have expected flexible labour markets such as in Anglo-Saxon countries to lead to better relative employment opportunities for the low-educated workers, here, this group of workers experience their highest disadvantage in Canada and the United States while in traditionally more rigid labour markets such as Germany, Finland, or Sweden, this employment disadvantage is either low or medium.

Now that we have obtained our dependent variable for the country-level analysis, we can examine the puzzling cross-national variation in the relative employment disadvantage of the low-educated workers, first by verifying each of our hypotheses separately, second by testing the validity of the skill hypotheses against the more traditional hypotheses linked to labour market institutions and policies. We would like to remind the reader that because of the small number of countries in the second stage of our analysis, the findings we present should be interpreted with caution. ${ }^{11}$

As we can observe in Table 2, only employment protection, job displacement, and the cognitive gap seem 


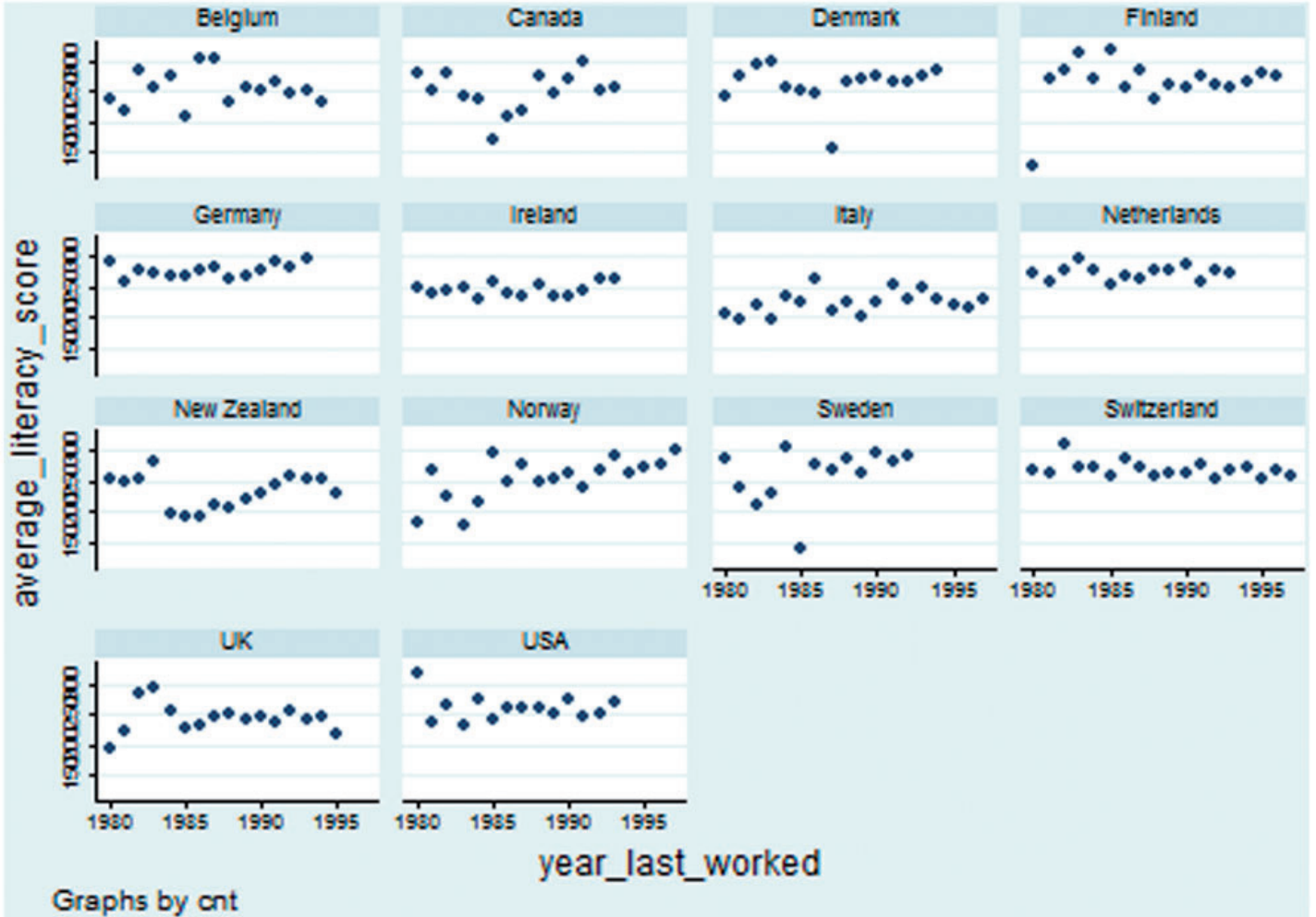

Figure 1 Average literacy scores depending on unemployment duration, by country Source: IALS 1994-1996-1998

Table 1 The relative employment disadvantage of the low-educated workers across countries

$\begin{array}{ll}\text { Year of survey } & n \\ \text { AME for ISCED } 3 \\ \text { (with controls) }\end{array}$

Standard errors

\begin{tabular}{lcccc}
\hline Germany & 1994 & 1056 & 0.03 & 0.0423 \\
Switzerland & 1994 and 1998 & 2545 & 0.06 & 0.0359 \\
Finland & 1998 & 1791 & 0.06 & 0.0267 \\
Netherlands & 1994 & 1894 & 0.08 & 0.0247 \\
UK & 1996 & 3794 & 0.09 & 0.0340 \\
New Zealand & 1996 & 1838 & 0.10 & 0.0282 \\
Sweden & 1994 & 1553 & 0.10 & 0.0268 \\
Belgium & 1996 & 1096 & 0.11 & 0.0356 \\
Denmark & 1998 & 1943 & 0.11 & 0.0245 \\
Norway & 1998 & 2081 & 0.12 & 0.0298 \\
Italy & 1998 & 1981 & 0.15 & 0.0266 \\
Ireland & 1994 & 1294 & 0.15 & 0.0318 \\
USA & 1994 & 1691 & 0.17 & 0.0406 \\
Canada & 1994 & 2272 & 0.23 & 0.0505 \\
\hline
\end{tabular}

Note: AMEs were estimated for those with intermediate education (ISCED 3) with the low-educated (ISCED 0-2) as a reference category. Controls included gender, age, parental background, immigrant status, and the size of the community. These coefficients must be interpreted as the per cent point change in the probability of being employed for those with intermediate education relatively to the low-educated. Observations are in ascending order of the inequality of employment opportunities across both these groups.

Source: IALS 1994-1996-1998. 
Table 2 Determinants of the relative employment disadvantage of the low-educated workers in modern economies: single hypothesis testing with standardized independent variables

\section{Standardized coefficients}

\begin{tabular}{|c|c|c|c|}
\hline \multicolumn{4}{|l|}{ Labour market institutions and policies } \\
\hline Permanent employment protection & $-0.0195^{\star}$ & 0.12 & 14 \\
\hline Social benefits generosity & -0.0128 & 0.01 & 14 \\
\hline ALMPs: pes and administration & -0.0102 & - & 14 \\
\hline ALMPs: training & -0.0066 & - & 14 \\
\hline \multicolumn{4}{|l|}{ Skills } \\
\hline Cognitive gap & $0.0303^{\star * *}$ & 0.39 & 14 \\
\hline Skill demand of jobs held by the low-educated & -0.0080 & 0.50 & 14 \\
\hline Skill demand of jobs held by the medium-educated & $0.0285^{\star}$ & & \\
\hline
\end{tabular}

${ }^{*} P<0.10 ;{ }^{* *} P<0.05 ;{ }^{* * *} P<0.01$.

Note: The adjusted $\mathrm{R}^{2}$ was not provided when it was negative, meaning that the impact of the independent variable included in our model was most likely trivial.

Source: IALS 1994-1996-1998.

to significantly affect the relative employment disadvantage of the low-educated workers-although the first two are only significant at the 10 per cent level. Concerning permanent employment protection, the negative relationship found is most likely spurious as employment protection is strongly and positively correlated to the cognitive gap. We will see later how the effect of this variable on our dependent variable varies once we include the cognitive gap simultaneously in the model.

However, as expected, the higher the skill demand of jobs occupied by medium-educated workers while the skill demand of jobs held by the low-educated workers is fixed, the greater the employment opportunities for the low-educated workers. In other words, the greater the job displacement phenomenon, the lower the employment chances for the low-educated workers.

Finally, our hypothesis on the cognitive gap seems to be verified as a one standard deviation positive change in the cognitive gap increases the employment disadvantage of the low-educated workers relatively to those with intermediate education by approximately 3 percentage points, which would clearly be a non-negligible variation for our dependent variable whose standard deviation is equivalent to 5 percentage points.

Yet, in order to be sure that the effect of the cognitive gap on the employment disadvantage of the loweducated workers is not confounded with other factors, or similarly, that the impact of labour market institutions and policies is not due to inequality of skills, we now test our hypotheses simultaneously to disentangle the effect of these characteristics at the national level.

In Table 3 we can observe the results of our new regressions. Only models that were significant were kept while models where one of the independent variables included did not bring any significant change or was itself clearly insignificant are not shown. Compared to the bivariate models, several changes are notable. First of all, except for model 4 , the effect of the cognitive gap remains statistically significant and relatively strong. More particularly, in the best model that we could obtain in terms of explained variance (model 5), the cognitive gap has the strongest effect on the employment disadvantage of the low-educated workers compared with the other covariates included. All in all, the multivariate analysis tends to confirm the robustness of the effect of the cognitive gap on the likelihood of employment of the low-educated workers and its predominance over our other hypotheses related to labour market institutions and policies.

However, according to model 4, controlling for the average skill demand of jobs held by medium-educated workers clearly reduces the effect of the cognitive gap on our dependent variable as it is almost halved compared with its effect in the bivariate model. Therefore, it appears that an important part of the impact of the cognitive disadvantage of the low-educated workers on their employability is due to the fact that these workers have to compete with workers with intermediate education for the same jobs. And since the former possess in average lower levels of cognitive skills, their employment chances are clearly hampered by this competition.

Controlling for the cognitive gap also gives two interesting results when compared to the bivariate models. First, the social benefits generosity index has now a positive and significant-albeit only at the 
Table 3 Determinants of the relative employment disadvantage of the low-educated workers in modern economies: simultaneous testing of hypotheses with standardized independent variables

Model 1 Model 2 Model $3 \quad$ Model $4 \quad$ Model 5

\begin{tabular}{|c|c|c|c|c|c|}
\hline Cognitive gap & $0.0332^{\star}$ & $0.0473^{* * *}$ & $0.0480^{* * *}$ & 0.0165 & $0.0322^{*}$ \\
\hline Permanent employment protection & -0.0036 & & & & \\
\hline Social benefits generosity & & $0.0201^{*}$ & & & \\
\hline ALMPs: training & & & $0.0229^{* *}$ & & 0.0151 \\
\hline Skill demand of jobs held by the medium-educated & & & & $-0.0247^{\star *}$ & -0.0179 \\
\hline Adjusted $\mathrm{R}^{2}$ & 0.34 & 0.45 & 0.56 & 0.59 & 0.64 \\
\hline$N$ & 14 & 14 & 14 & 14 & 14 \\
\hline
\end{tabular}

${ }^{*} P<0.10 ;{ }^{* *} P<0.05 ;{ }^{* *} P<0.01$.

Source: IALS 1994-1996.

10 per cent level-impact on the employment disadvantage of the low-educated workers, as could be expected from our hypothesis. However, the fact that spending on training ALMPs seems to reduce the likelihood of employment of the low-educated workers compared with medium-educated workers is rather surprising and contradicts our theoretical expectations. Putting aside the fact that this effect is mainly due to the three Scandinavian countries, it is possible to find two reasons why the employment prospects of the low-educated workers should be less enhanced than those of their more educated counterparts by ALMPs. First, the latter seem to be more successful in getting a job and keeping it with the help of these policies than the former (Martin and Grubb, 2001; Gaure, Røed and Westlie, 2008; Nordlund, 2011). Second, the participation rates to ALMPs are generally higher for those with intermediate education than for low-educated workers (Amoroso and Witte, 1998; Crépon, Ferracci and Fougère, 2007). Therefore, these arguments support our evidence that training policies profit essentially to those with intermediate or higher education rather than the low-educated workers, who, sadly, need these policies the most. This finding is also in accordance to the claims of Heckman (2006), suggesting that investments in the human capital of individuals is essentially a matter of timing as it may yield higher returns the younger they are. And this would imply that it is the cognitive skills of individuals, whose development is crucial during the earliest periods of life, that predominates over training ALMPs whose success for the employment outcomes of the unemployed is probably also dependent on the level of general skills they possess.

Finally, model 1 suggests that the negative impact the strictness of permanent employment legislation has on the relative employment disadvantage of the loweducated workers is mainly explained by the fact that countries with high employment protection are also characterized by a low cognitive gap. This finding therefore confirms that the negative relationship we found between this variable and the employment disadvantage of the low-educated workers in the bivariate model was indeed spurious.

\section{Conclusion and Discussion}

As our results indicate, it therefore appears that the greater the cognitive gap between the low-educated workers and workers with intermediate education, the higher the risk that the former will be statistically discriminated by employers or will simply be disadvantaged at the individual level in terms of employability. In other words, employers are probably more likely to hire and keep employees depending on their formal educational qualifications when higher qualifications denote better skills. If the boundary between skill levels of different educational groups is blurrier, employers will tend to discriminate less according to formal educational credentials in order to hire workers, implying, as Farkas et al. (1997) note, that employers may succeed in solving their information problems concerning the skill level of workers.

Moreover, even after accounting for labour market regulation, this relationship remains significant and strong. However, almost half of the effect of the cognitive gap seems to be explained by the extent to which the medium-educated crowd out low-educated workers from their traditional occupations. Finally, once the cognitive gap is accounted for, training ALMPs seem to work best for those with intermediate education, creating a Matthew effect, as already noted in previous studies on the matter, and thus pointing at the need to improve the basic skills of the low-educated workers in order to enhance the effectiveness of the training ALMPs in their case. 
All in all, our results thus seem to point at the need to reduce this cognitive gap if we want to give the low-educated workers better employment opportunities. In order to do so, governments should try to reduce between-school inequality in resources such as class size or teachers' experience as pupils from disadvantaged background, who incur higher risks of leaving school with low educational qualifications, are also more likely to attend low-quality schools (Park and Kyei, 2011). Moreover, since inequalities in cognitive skills already appear during the preschool period as a result of inequalities in parental economic and social background, policymakers should target disadvantaged young children through the implementation of a set of family policies that aims at increasing their development and their future life chances (Esping-Andersen, 2009, ch. IV). Furthermore, since cognitive skills also seem to play a determinant role in educational attainment (Heckman, Stixrud and Urzua, 2006), investing in those skills may constitute a good way to weaken the link between parental background and educational attainment. However, governments wishing to improve the employment situation of the low-educated workers should not forget the prevention of skill mismatches in the labour market and should thus avoid the development of heavy job displacement patterns through, for instance, a more adequate and strong articulation between educational systems and labour markets.

\section{Notes}

1 It is important to note that in IALS, the classification was ISCED 76, not ISCED 97.

2 The author thanks Ralf Künster for providing him with the SPSS code to perform this recoding.

3 In order to check for the robustness of our results despite this recoding, we excluded both these countries of our analysis. Since we obtained the same results, we are confident that our findings are robust.

4 We did not control for cognitive skills at the individual level as they explained most of the effect of education on employment status in some countries and caused the reduction of cross-national variation in the employment disadvantage of the low-educated workers, thus indicating that the individual-level effect of cognitive skills is key in the explanation of this puzzle. Cognitive skills were thus only integrated at the country-level. However, to account for the fact that for workers with similar educational attainment they may also vary according to age or parental background, we used adjusted means to obtain our index of the cognitive gap (see note 7).

5 See the appendix for descriptive statistics of these variables.

6 Instead of using spending on ALMPs as our indicator, we prefer to disaggregate this measure as many studies now show that it clearly makes no sense using it as a whole, since the categories that comprise it assess very different policies (e.g. Bonoli, 2010; Vlandas, 2011). Therefore, we use two categories which, according to us, better represent the potential benefits of those policies for the low-educated workers, namely training and public employment service and administration.

7 Average literacy scores were calculated using adjusted means that were obtained through predicted values of a regression of literacy scores against age, gender, immigration status, and parental background for each educational level (low and medium) and each country. This method helps us account for a part of the individual variation in scores for a given educational level and country. It thus also accounts for the fact that educational systems evolve over time, making the comparison between the low-educated workers of different age groups easier, or for the fact that individuals from disadvantaged background possess lower levels of skills, all other things being equal.

8 In order to do so, we simply averaged the 15 plausible values of the different literacy scores.

9 The skill demand of jobs was measured through principal component analysis of a series of questions on the frequency of use of literacy skills at work. More precisely, respondents were asked how often a week they had to use reading, writing, and arithmetic skills as a part of their job. For more details, we refer to the IALS documentation available on the Statistics Canada website: http://www.statcan.gc.ca/.

10 Moreover, since we control for age in our analysis, this should solve part of the potential bias.

11 Omitted variable bias as well as heteroskedasticity tests were performed and both gave satisfying results for most of the models. Some models were subject to heteroskedasticity but the use of hc3 robust standard errors easily corrected this problem. 
Multicollinearity tests were also performed and did not exhibit any problem.

\section{Acknowledgements}

The author wishes to thank Giuliano Bonoli, John Stephens, Patrick Emmenegger, Daniel Oesch, Michael Gebel, Nils Soguel and the anonymous reviewers for their helpful comments and suggestions regarding the paper.

\section{References}

Amoroso, L. M. and Witte, J. C. (1998). German Active Labor Market Policies: The Use of Job Creation and Training Programs Following Unification. In Galler, H. P. and Wagner, G. (Eds.), Empirische Forschung und wirtschaftspolitische Beratung: Festschrift für Hans-Jürgen Krupp zum 65. Geburtstag, Reihe Wirtschaftswissenschaften. Frankfurt and New York: CAMPUS-Verlag, pp. 200-214.

Autor, D. H. and Dorn, D. (2009). The Growth of Low Skill Service Jobs and the Polarization of the U.S. Labor Market. Working Paper No. w15150. Cambridge: National Bureau of Economic Research.

Autor, D. H., Levy, F. and Murnane, R. J. (2003). The skill content of recent technological change: an empirical exploration. The Quarterly Journal of Economics, 118, 1279-1333.

Bonoli, G. (2007). Time matters: postindustrialiszation, new social risks, and welfare state adaptation in advanced industrial democracies. Comparative Political Studies, 40, 495-520.

Bonoli, G. (2010). The political economy of active labor-market policy. Politics and Society, 38, 435-457.

Bradley, D. H. and Stephens, J. D. (2007). Employment performance in OECD countries: a test of neoliberal and institutionalist hypotheses. Comparative Political Studies, 40, 1-25.

Carbonaro, W. (2007). The effects of education and cognitive skills on earnings: how much do occupations and jobs matter? Research in Social Stratification and Mobility, 25, 57-71.

Crépon, B., Ferracci, M. and Fougère, D. (2007). Training the Unemployed in France: How Does It Affect Unemployment Duration and Recurrence? Discussion Paper No. 3215. Bonn: Institute for the Study of Labor.

Daly, M. (2000). Economic changes, vulnerabilities, and institutional capabilities. In Scharpf, F. W. and Schmidt, V. A. (Eds.), Welfare and Work in the
Open Economy Vol.II: Diverse Responses to Common Challenges in Twelve Countries. Oxford: Oxford University Press, pp. 467-510.

De Grip, A. and Zwick, T. (2004). The Employability of Low-Skilled Workers in the Knowledge Economy. Paper presented at the LoWER 2004 Conference, London School of Economics, April 23-24, available from: $<$ http://rlab.lse.ac.uk/lower/final_papers/grip.pdf> [Accessed 28 February 2012].

DiPrete, T. A. (2005). Labor markets, inequality, and change: a European perspective. Work and Occupations, 32, 119-139.

Esping-Andersen, G. (2000). Who is harmed by labour market regulations? In Esping-Andersen, G. and Regini, M. (Eds.), Why Deregulate Labour Markets? Oxford: Oxford University Press, pp. 66-98.

Esping-Andersen, G. (2009). The Incomplete Revolution: Adapting to Women's New Roles. Cambridge: Polity Press, pp. 111-144.

Farkas, G., England, P., Vicknair, K. and Kilbourne, B. S. (1997). Cognitive skill, skill demand of jobs, and earnings among young European American, African American, and Mexican American workers. Social Forces, 75, 913-938.

Gaure, S., Røed, K. and Westlie, L. (2008). The Impacts of Labor Market Policies on Job Search Behavior and Post-Unemployment Job Qualiy. Discussion Paper No. 3802. Bonn: Institute for the Study of Labor.

Gebel, M. and Giesecke, J. (2011). Labor market flexibility and inequality: the changing skill-based temporary employment and unemployment risks in Europe. Social Forces, 90, 17-40.

Gesthuizen, M., Solga, H. and Künster, R. (2011). Context matters: economic marginalization of low-educated workers in cross-national perspective. European Sociological Review, 27, 264-280.

Heckman, J. J. (2000). Policies to foster human capital. Research in Economics, 54, 3-56.

Heckman, J. J. (2006). Skill formation and the economics of investing in disadvantaged children. Science, 312, 1900-1902.

Heckman, J. J., Stixrud, J. and Urzua, S. (2006). The effects of cognitive and noncognitive abilities on labor market outcomes and social behaviour. Journal of Labor Economics, 24, 411-482.

Howell, D. R. (2003). The micro-foundations of high unemployment in developed countries: Are labor market rigidities the problem? In Harris, J. M. and Goodwin, N. R. (Eds.), New Thinking in Macroeconomics: Social, Institutional and Environmental Perspectives. Cheltenham: Edward Elgar Publishing Limited, pp. 123-157. 
Huber, E. and Stephens, J. D. (2006). Combating old and new social risks. In Armingeon, $\mathrm{K}$. and Bonoli, G. (Eds.), The Politics of Post-Industrial Welfare States: Adapting Post-War Social Policies to New Social Risks. Oxon: Routledge, pp. 143-168.

Leoni, E. L. (2009). Analyzing Multiple Surveys: Results from Monte Carlo Experiments. unpublished paper, available from: <http://eduardoleoni.com/working papers/multilevel.pdf $>$ [Accessed 28 February 2012].

Lewis, J. B. and Linzer, D. A. (2005). Estimating regression models in which the dependent variable is based on estimates. Political Analysis, 13, 345-364.

Long, J. S. and Ervin, L. H. (2000). Using heteroscedasticity consistent standard errors in the linear regression model. The American Statistician, 54, 217-224.

Maas, C. J. M. and Hox, J. J. (2004). Robustness issues in multilevel regression analysis. Statistica Neerlandica, 58, 127-137.

Machin, S. and Manning, A. (1998). The Causes and Consequences of Long-Term Unemployment in Europe. Discussion Papers No. 400. London: Centre for Economic Performance.

Martin, J. P. and Grubb, D. (2001). What works and for whom: a review of OECD countries' experiences with active labour market policies. Swedish Economic Policy Review, 8, 9-56.

McIntosh, S. and Vignoles, A. (2000). Measuring and Assessing the Impact of Basic Skills on Labour Market Outcomes. Centre for the Economics of Education, available from: http://cee.lse.ac.uk/ceedps/ceedp03 .pdf [Accessed 28 February 2012].

Mood, C. (2010). Logisitic regression: why we cannot do what we think we can do and what we can do about it. European Sociological Review, 26, 67-82.

Murnane, R. J., Willett, J. B. and Levy, F. (1995). The growing importance of cognitive skills in wage determination. The Review of Economics and Statistics, 77, 251-266.

Nelson, M. (2009). An application of the estimated dependent variable approach: trade union members' support for active labor market policies and insider-outsider politics. International Journal of Public Opinion Research, 21, 224-234.

Nordlund, M. (2011). Who are the lucky ones? Heterogeneity in active labour market policy outcomes. International Journal of Social Welfare, 20, 144-155.

Park, H. and Kiey, P. (2011). Literacy gaps by educational attainment: a cross-national analysis. Social Forces, 89, 879-904.

OECD (1994). The OECD Jobs Study. Paris: OECD.

OECD (2002). OECD Employment Outlook 2002. Paris: OECD.

OECD (2011). OECD Education at a Glance 2011. Paris: OECD.

Oesch, D. (2010). What explains high unemployment among low-skilled workers? Evidence from 21 OECD countries. European Journal of Industrial Relations, 16, 39-55.

Oesch, D. and Menés, J. R. (2010). Upgrading or polarization? Occupational change in Britain, Germany, Spain and Switzerland, 1990-2008. Socio-Economic Review, 9, 503-532.

Pryor, F. L. and Schaffer, D. L. (1999). Who's Not Working and Why: Employment, Cognitive Skills, Wages, and the Changing U.S. Labor Market. Cambridge: Cambridge University Press.

Scruggs, L. and Allan, J. (2006). Welfare-state decommodification in 18 OECD countries: a replication and revision. Journal of European Social Policy, 16, 55-72.

Siebert, H. (1997). Labor market rigidities: at the root of unemployment in Europe. Journal of Economic Perspectives, 11, 37-54.

Solga, H. (2002). 'Stigmatization by negative selection'. Explaining less-educated people's decreasing employment opportunities. European Sociological Review, 18, 159-178.

Vlandas, T. (2011). The Dependent Variable Problem in Quantitative Studies of Active Labour Market Programmes: Uncovering Hidden Dynamics? Working Papers on the Reconciliation of Work and Welfare in Europe, REC-WP 03/2011. 


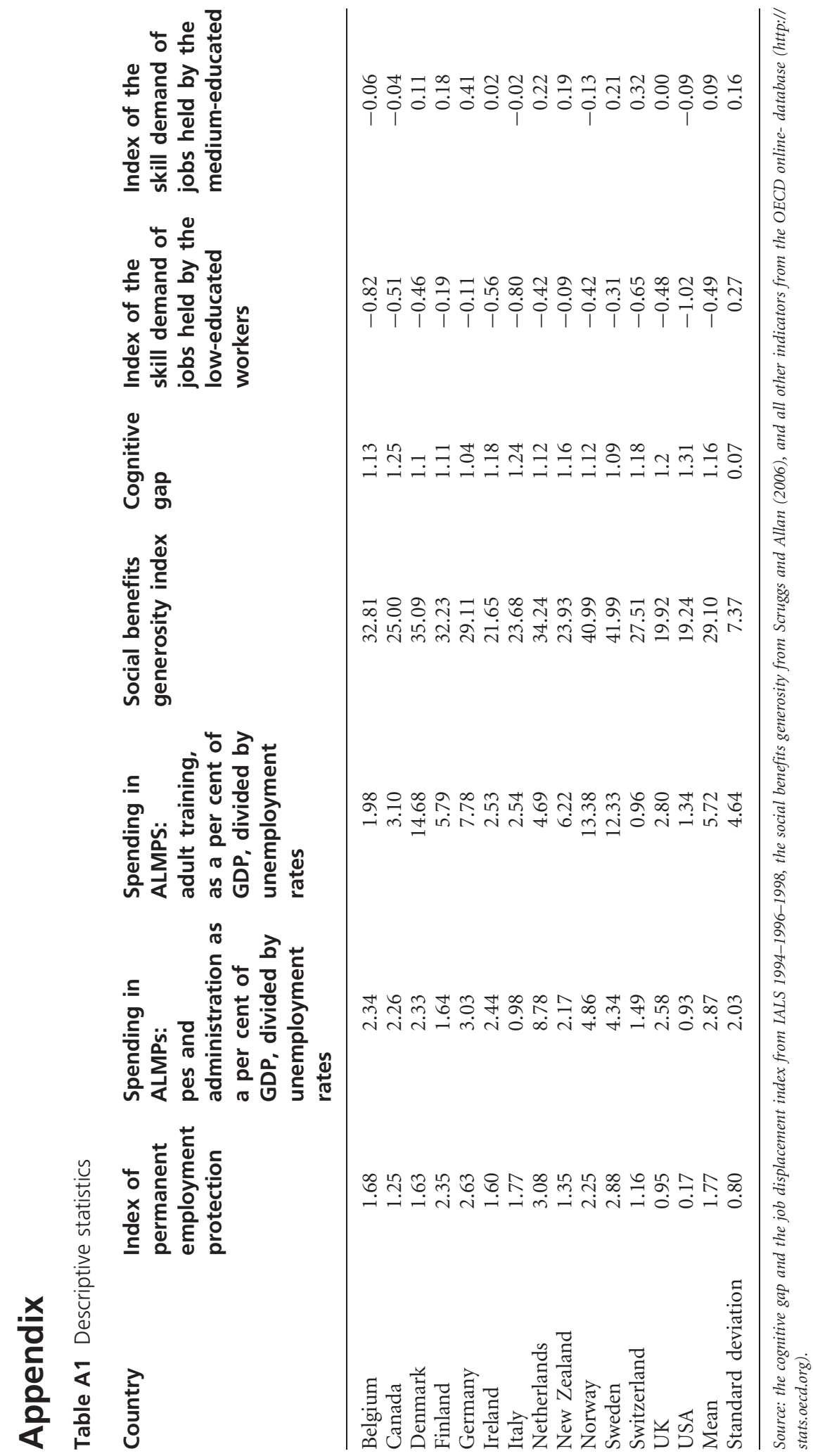

